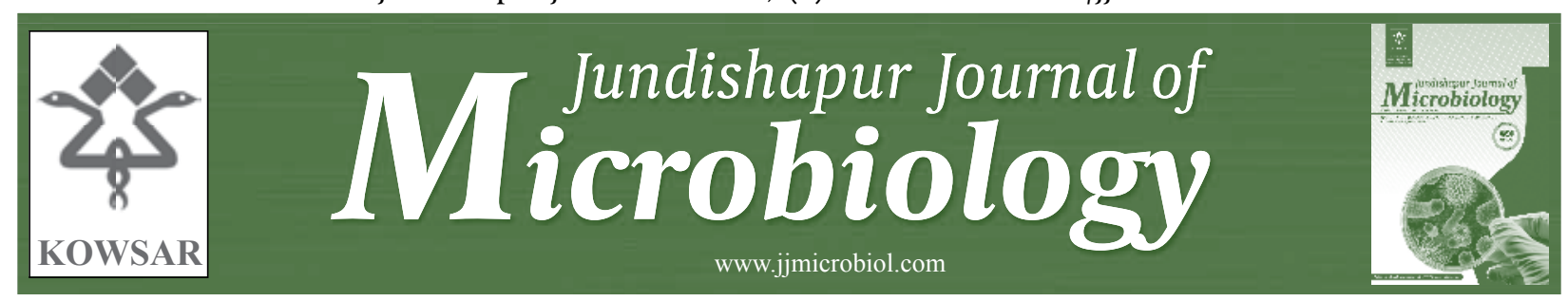

\title{
Indexing in ISI Web of Sciences: The Opportunities and Threats
}

\author{
Seyyed Mohammad Miri ${ }^{1,2}$, Parisa Bahmani ${ }^{3^{*}}$ \\ ${ }^{1}$ Baqiyatallah Research Center for Gastroenterology and Liver Diseases, Tehran, IR Iran \\ ${ }^{2}$ Kowsar Corporation, Central Office, Hoensbroek, Netherlands \\ ${ }^{3}$ Kowsar Corporation, Regional Office, Tehran, IR Iran
}

\section{A R T I C L E I N F O}

Article type:

Editorial

\section{Article history:}

Received: 01 Mar 2012

Revised: 05 Mar 2012

Accepted: 09 Mar 2012

Keywords:

Journal Impact Factor

\section{Introduction}

The Institute for Scientific Information (ISI) as a citation databases covers over 8000 international journals following a basic task of providing comprehensive coverage of the world's most important and influential research and helping researchers to identify high and frequently cited articles (1). The mission of ISI editorial team is to identify and evaluate promising new journals that will be useful to ISI subscribers, and rejecting journals that have become less useful. The ISI Database also publishes the annual journal citation reports which list an impact factor for each of the journals that it tracks. Beside the scientific team, journal impact factors play a large but controversial role in determining the dignity of a scientist's published research record.

Comparable to the ISI as a citation database, there are other major and well-known databases such as PubMed and Scopus. Specifically in the field of medicine, the National Library of Medicine (NLM) introduced the first interactive searchable database with coverage of publications since 1950 which has become the most popular and one of the most reliable WWW resources for clinicians and researchers. On the other hand, Scopus was also

\footnotetext{
* Corresponding author: Parisa Bahmani, Patersweg 22, 6431GC, Hoensbroek, Netherlands. Tel/Fax:+31-1455216399, E-mail: bahmani.parisa@ gmail.com

DOI:10.5812/jjm.5116

Copyright $\odot 2012$ Kowsar Corp. All rights reserved.
}

Implication for health policy/practice/research/medical education:

The article focuses on the importance of indexing a Journal in the ISI Web of Sciences amd discuss some disadvantages.

- Please cite this paper as:

Miri SM, Bahmani P. Indexing in ISI Web of Sciences: The Opportunities and Threats. Jundishapur J Microbiol. 2012;5(2): 381-3. DOI: $10.5812 / j j m .5116$

Copyright $\odot 2012$ Kowsar Corp. All rights reserved.

launched to the Internet in 2004 by Elsevier as one of the alternative to Thomson ISI's Web of Science.

The most important strength of the ISI is its citation analysis presented with excellent graphics and more detailed than the other sources probably because Web of Science has been focused more in scientometrics. ISI impact factor introduction has totally changed the measurement of scientifical citation rates. Public closed access is One of the ISI weaknesses. Controversially PubMed acts as an actual convenient, quick, and easy to use database. The fact that PubMed is free and the authority it has gained through the years have made it the most frequently used resource for information in the biomedical field(2). According to the number of records leading to citation analysis, ISI citation analysis is slower and includes less articles than the other citation analysis titled Scopus(2). The major disadvantage of the Web of Science is that it may provide a substantial underestimation of an individual academic's actual citation impact. Differences will not be as dramatic for all scholars, but many academics show a substantially higher number of citations in Google Scholar than in the Web of Science. For instance Nisonger found that (3) Web of Science captured only $28.8 \%$ of his total citations, $42.2 \%$ of his print citations, $20.3 \%$ of his citations from outside the United States, and a mere $2.3 \%$ of his non-English citations. Actually librarians and faculty should not rely solely on Web of Science author citation counts, especially when demonstration 
of international impact is important. The relatively small overlap in citations between the three databases (Scholar, Scopus and ISI) caused by the fact that Google Scholar produced more than twice as many citations as Web of Science and nearly twice as many citations as Scopus(6). Based on Saad (4) on 55 scientists most academics' h-indices are underestimated by a similar magnitude by Web of Science. In the General Search function Web of Science only includes citations to journal articles published in ISI listed journals (5). Citations to books, book chapters, dissertations, theses, working papers, reports, conference papers, and journal articles published in non-ISI journals are not included (6). In the Cited Reference function Web of Science does include citations to non-ISI publications. However, it only includes citations from journals that are ISI-listed (7). Archambault \& Gagné (8) found that US and UK-based journals are both significantly over-represented in the Web of Science in comparison to Ulrich's journal database. Further, in many areas of engineering, conference proceedings are very important publication outlets. Whilst the Cited Reference function of Web of Science does include citations to non-ISI journals, it only includes these publications for the first author. Hence any publications in non-ISI journals where the academic in question is the second or further author are not included. The Web of Science includes only a very limited number of journals in languages other than English (LOTE) and hence citations in non-English journals are generally not included in any Web of Science citation analysis. Whereas Google Scholar's LOTE coverage is far from comprehensive, it does include a larger number of publication in languages other than English and also indexes documents in French, German, Spanish, Italian and Portuguese (9).

Since the early 2009 as the first attempt for indexing in ISI web of science, 107 articles published in the Jundishapur journal of Microbiology and have been indexed in the ISI web of sciences. Iran is one of the most rapidly developing countries with a high number of researchers. According to a survey on the number of scientific publications listed in the ISI Web of Science Iran achieved the fastest scientific growth in 2010 (10). Moreover Iran publication records show a $20 \%$ increase compared to its 2010 publication records which is the largest increased amongst the top 40 countries (1). These reported numbers are just for 2011, but Iran, Turkey and Egypt have been showing a consistent increase in their science papers over the past 10 years (11).

\section{Do We Need More Journals in the Same Field?}

By searching the journal citation reports (2010 Science Edition, ISI), by limiting the journal search results specifically in the category of "Microbiology" there are 107 journals indexed in ISI while among allthese indexed journals merely one Iranian journal in the same field is avavilable. according to the number of journals there would be a huge gap.

On the other hand, searching the term "Microbiology" in the topic of all records in ISI web of knowledge indicates that 15372 related articles have been indexed till now. This survey shows that the number of published articles by Iranian researchers have been increased slightly. Using another citation database like PubMed showed that until now 1878 articles are indexed in PubMed when we used microbiology AND Iran (limited in the authors' address field) as the searching keyword. Either ISI or PubMed results indicates that number of published articles by Iranian researchers are not sufficient for Iranian searching purposes (Figure 1). Concerning to the importance of the presence of more prestigious journals in the microbiology and the high number of researches in the field establishment of other journals is mandatory.

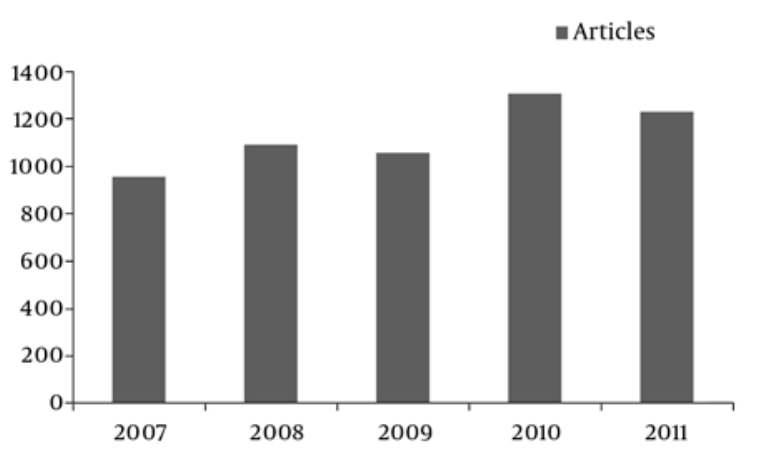

Figure 1. Trend of Articles Found With The Query of Microbiology And Iran Searched in PubMed Between 2007 and 2011

By focusing on 50 Iranian medical universities and 15 Iranian research centers in the field of microbiology, illustrated the number of researchers are not even equal to the number of regional journals because assuming an average of 10 researchers in each center working on three research projects per year, it is expected to lead an annual publication of 150-300 manuscripts.

Iranian scientists have always been great contributors ofthe evolution of tradition, religion and experiences based sciences. Since a large number of research projects conducted in Iran have been traditionally published in Persian language journals, their results obviously would only cover a minority of all published articles worldwide. Since the mid-2000s, a drastic increase in the number of scientific papers published in international journals especially in the field of biomedical research from Iran has been reported.However, the number of world wellknown journals which appear to be supportive of the continuous increasing Iranian medical literatures is not satisfactory.

\section{References}

1. Web of Science. Wikipedia, the free encyclopedia. [12 March 2012]; Available from: http://en.wikipedia.org/wiki/Web_of_Science.

2. Falagas ME, Pitsouni EI, Malietzis GA, Pappas G. Comparison of PubMed, Scopus, Web of Science, and Google Scholar: strengths 
and weaknesses. FASEB J. 2008;22:338-42.

3. Nisonger TE. Citation Autobiography: An Investigation of ISI Database Coverage in Determining Author Citedness. College \& Research Libraries. 2004;65(2):152-63.

4. Saad G. Exploring the h-index at the author and journal levels using bibliometric data of productive consumer scholars and business-related journals respectively. Scientometrics. 2006;69(1):117-20.

5. Roediger BHL. The $\mathrm{h}$ Index in Science: A New Measure of Scholarly Contribution. APS Observer:The Academic Observer. 2006;19(4).

6. Belew RK. Scientific impact quantity and quality: Analysis of two sources of bibliographic data. arXiv\#: CoRR/0504036. 2005.
7. Meho LI. The rise and rise of citation analysis. 2007.

8. Archambault E, Gagné EV. The Use of Bibliometrics in Social Sciences and Humanities, Montreal: Social Sciences and Humanities Research Council of Canada (SSHRCC). 2004.

9. Noruzi A. Google Scholar : the new generation of citation indexes. LIBRI. 2005;55(4):170 - 80

10. MacKenzie D. Iran showing fastest scientific growth of any country. 2010 [updated 2010]; Available from: http://www.newscientist.com/article/dn18546-iran-showing-fastest-scientific-growthof-any-country.html.

11. Noorden RV. 365 days: 2011 in review. Nature. 2011;480:429. 